\title{
W-plasty: An Important Tool for Cross-Hatch Marks
}

\author{
Kapil Agrawal ${ }^{1}$ Raghav Shrotriya ${ }^{1, \oplus}$ Makrand Thakre ${ }^{1}$ Vinita Puri ${ }^{1}$
}

1Department of Plastic Surgery, Seth Gordhandas Sunderdas Medical College and King Edward Memorial Hospital, Mumbai, Maharashtra, India

Indian J Plast Surg 2021;54:246-247.

Unsightly scars are a major cause for concern in complete recovery after trauma. Particularly troublesome are cross-hatch marks caused by tight sutures left in situ for long. Revision of such scars can be challenging for plastic surgeons. The conventional fusiform excision is not preferable, due to unnecessary excision of the normal skin in between the scar marks. The resultant scar may be under tension and remains as a straight line which may not align with resting skin tension lines (RSTL). The authors use W-plasty for revision of such scars. Revision of hatch marked scars was done in 25 patients over a period of 5 years (from January 2013 to January 2020). They observed satisfactory improvement in scar appearance at conversational distance as seen in preoperative (-Fig. 1, - Fig. 2) and postoperative pictures (-Fig. 3, -Fig. 4).

In W-plasty, straight or curved antitension line scar is converted to zigzag pattern without tissue rotation or lengthening. It involves small incisions linked at sharp angles taken

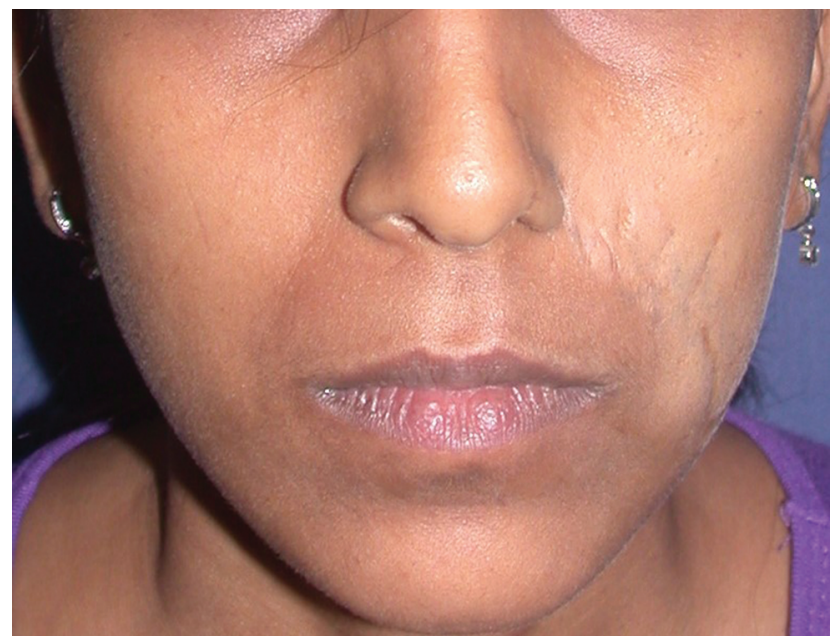

Fig. 1 Preoperative frontal view photograph showing cross-hatched mark scars.

published online June 22, 2021
DOI https://doi.org/

$10.1055 / \mathrm{s}-0041-1729664$ ISSN 0970-0358
Address for correspondence Raghav Shrotriya, MS, MCh, Department of Plastic Surgery, Seth Gordhandas Sunderdas Medical College and King Edward Memorial Hospital, Mumbai 400012, Maharashtra, India (e-mail: dr.raghav.s@gmail.com).

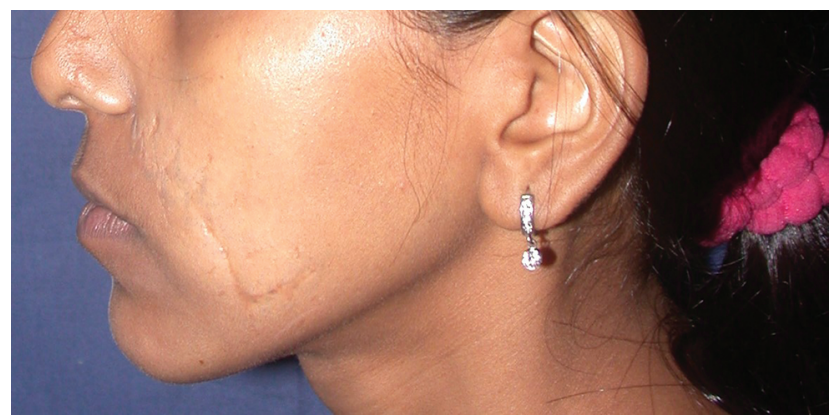

Fig. 2 Preoperative lateral view photograph showing cross-hatched mark scars.

at both sides of the scar (-Fig. 5). The intervening strip is excised as a zigzag strip. Running W units should be placed as close to the scar as possible to minimize wastage of unscarred skin. In cross-hatch marks, "diamond shaped" excision includes the whole scar and leaves out unscarred skin. To suture the apices of triangular flaps to the notches, one side skin needs to be pulled laterally. This leads to dog ears at the edges which can be managed by excision of Ammon's triangle (lies at one end of a quadrilateral defect or at the base of a triangular defect to convert it to a fusiform shape). ${ }^{1}$

Excision is done up to the level of dermis so that strength of elastin and collagen can be utilized in suturing (-Fig. 6). During closure, taking subcuticular stitches running between triangular flaps at a level midway between the tip and the base is advisable. Skin can be closed by interrupted nonabsorbable sutures only at the tips. Care should be taken to ensure that the sutures are not too tight, do not invert the edges, and are removed on the fifth postoperative day followed by taping across the suture line. It is continued for 2 weeks. Scar massage is advised after the third postoperative week.

Borges first described W-plasty for improving antitension line scars in $1958 .^{2}$ The $\mathrm{W}$-plasty technique converts a single linear scar into a zigzag scar which is less visible because half
(C) 2021. Association of Plastic Surgeons of India.

This is an open access article published by Thieme under the terms of the Creative Commons Attribution-NonDerivative-NonCommercial-License, permitting copying and reproduction so long as the original work is given appropriate credit. Contents may not be used for commercial purposes, or adapted, remixed, transformed or built upon. (https://creativecommons.org/licenses/by-nc-nd/4.0/).

Thieme Medical and Scientific Publishers Pvt. Ltd. A-12, 2nd Floor, Sector 2, Noida-201301 UP, India 


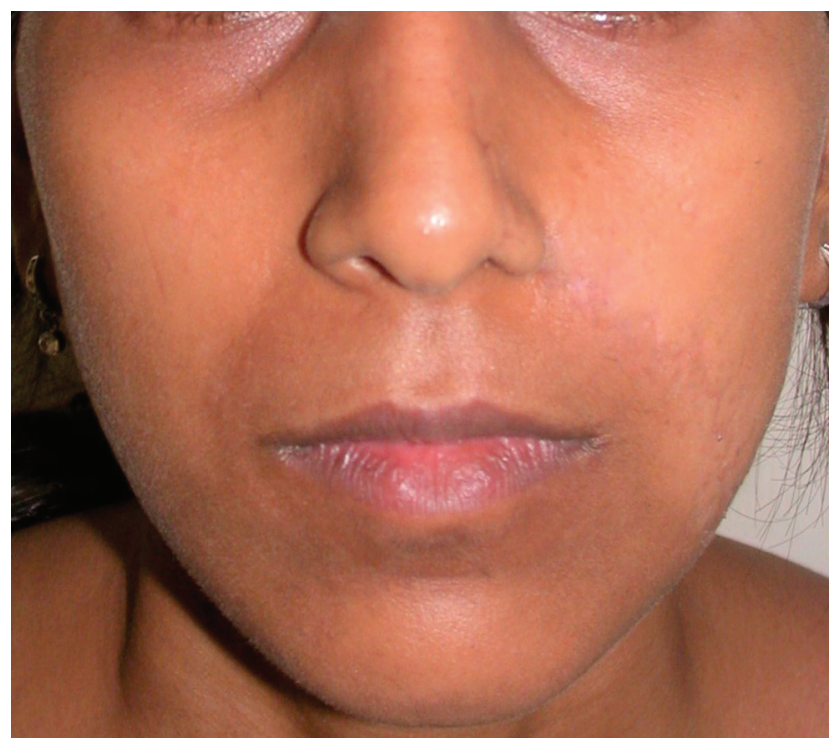

Fig. 3 Fourteen months postoperative frontal view photograph. Hatch marks have been removed and the scar is less conspicuous.

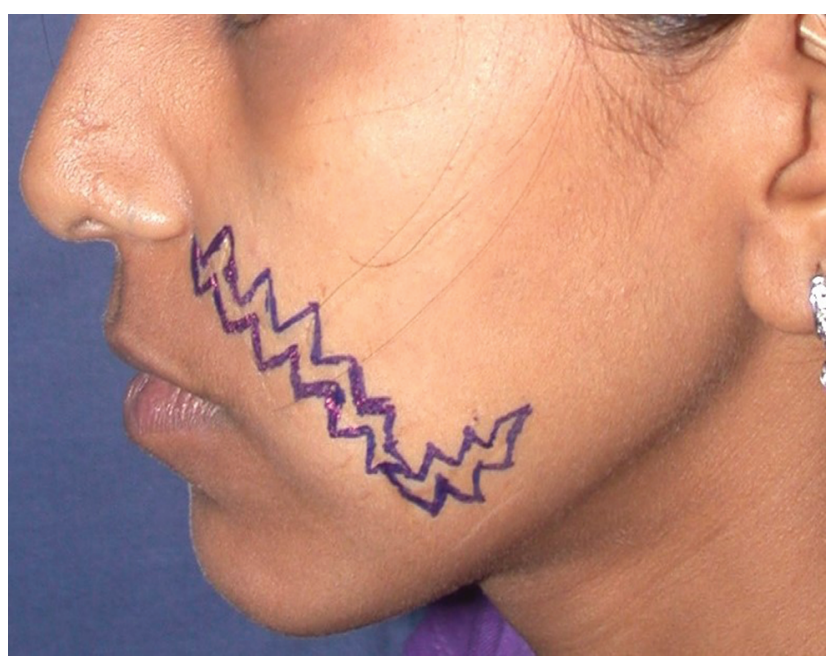

Fig. 5 Marking of W-plasty incision.

the segments parallel to RSTLs are concealed and the other half which are obliquely oriented are less visible as broken lines. Preoperatively it is necessary to mark out RSTLs and note their relative orientation with the scar. Preferably, one of the sides of the triangle should be kept parallel to the RSTL. Some authors advocate site-specific design modification for the triangles along same principle. ${ }^{3}$ Thus, the use of W-plasty allows us to remove all cross-hatch marks in the same setting (thereby minimizing wastage of intervening skin) and also makes the scar inconspicuous. Awareness of RSTLs and careful planning of the excision marking goes a long way in ensuring optimal results.

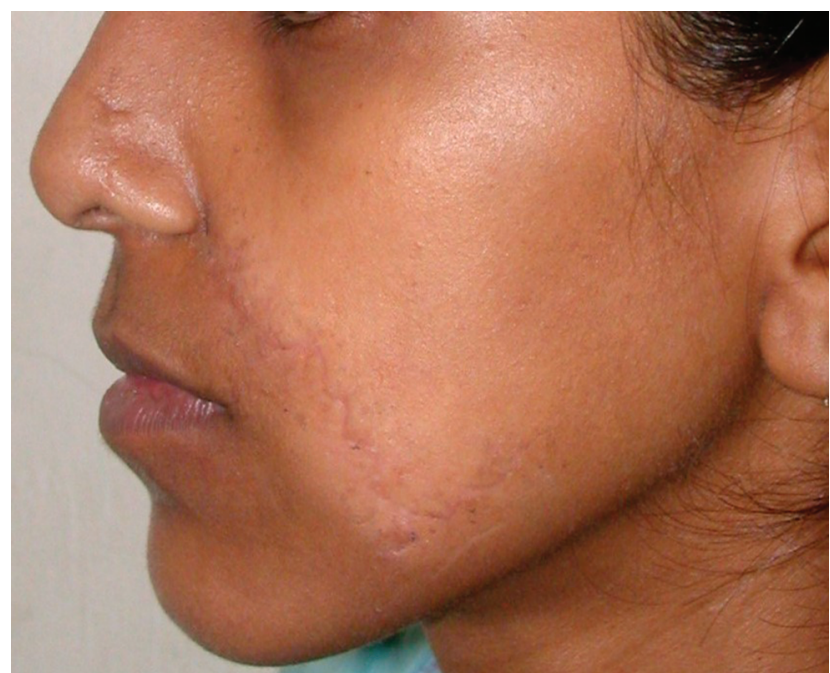

Fig. 4 Fourteen months postoperative lateral view photograph. Hatch marks have been removed and the scar is less conspicuous.

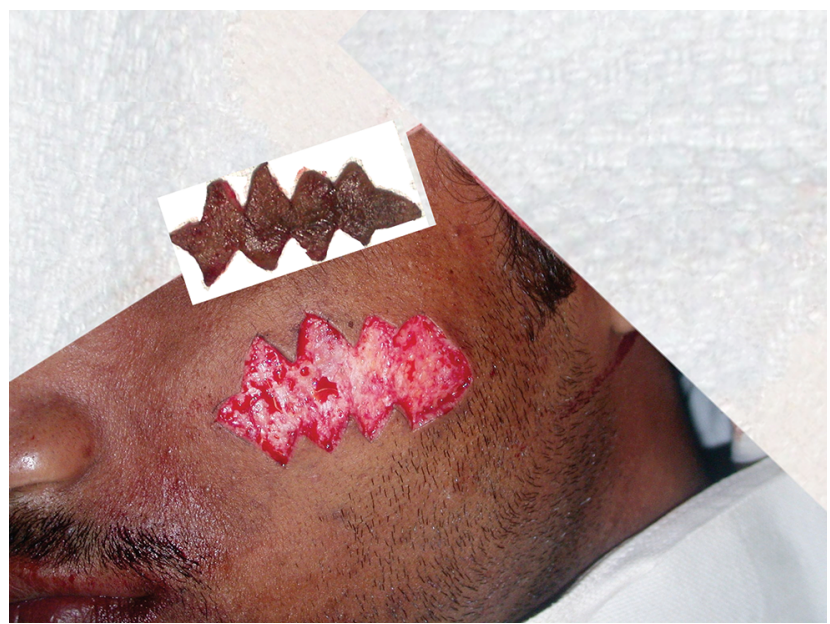

Fig. 6 Photograph of a different patient showing excised strip of scar and resulting raw area. Note that part of dermis is left behind.

\section{Conflict of Interest}

None declared.

\section{References}

1 Borges AF, W-plastic scar revision. In: Elective Incisions and Scar Revisions. 1st ed. Boston, MA: Little, Brown and Company; 1973:177-196

2 Borges AF. Cirurgia plastica de una herida cutanea. Rev Confed Med Panam 1958;5(1):56-58

3 Goutos I, Yousif AH, Ogawa R. W-plasty in scar revision: geometrical considerations and suggestions for site-specific design modifications. Plast Reconstr Surg Glob Open 2019;7(4):e2179 